\title{
DINÂMICA INDUSTRIAL E IMPLICAÇÕES SOCIOESPACIAIS EM HUMILDES, FEIRA DE SANTANA/BA: PROCESSOS E AÇÕES
}

\author{
Vanessa da Conceição Barbosa dos Anjos \\ Graduanda em Geografia/UEFS. \\ vanessa.124@hotmail.com
}

\author{
Janio Santos \\ Doutor em Geografia, Professor Titular/DCHF-UEFS; \\ E-mail: janiosantos@yahoo.com.br
}

Palavras-Chave: Formação, Humildes, Desenvolvimento, Urbanização.

\section{INTRODUÇÃO}

O espaço é um meio social no qual o homem se apropria, transformando-o, através do trabalho; ou seja, é o lugar material resultado das relações que os homens estabelecem entre si, estando inserido nas contradições e desigualdades sociais. O espaço urbano aparece assim, diante de um conjunto de usos que redundam, por exemplo, na organização espacial da cidade, na materialização das relações sociais e na divisão social do trabalho, na medida em que, a cidade é forma e conteúdo do espaço urbano.

Diante disso há ocorrência de diversos processos que impulsionaram o desenvolvimento da cidade de Feira de Santana. A atividade industrial ocupa papel importante na alteração do espaço urbano, sendo responsável por profundas alterações na divisão social, territorial e técnica do trabalho, o que implica em novas configurações socioespacias, associadas sobremodo à reprodução do capital. Desse modo, o crescimento do capital industrial pode trazer à cidade mudanças significativas, que, nesse sentido, apresentará em suas formas e conteúdos reflexos das mudanças da/na sociedade, em sua totalidade.

Feira de Santana, caso particular estudado, possui aspectos determinantes que contribuem para compreender o desenvolvimento da cidade, já que é sede de um importante polo de desenvolvimento industrial. Esse polo é formado por três núcleos: Tomba que se situa entre o anel de contorno rodoviário e a linha divisória Feira de Santana/São Gonçalo dos Campos; o de São Gonçalo dos Campos, que está localizado entre o Sul de Feira de Santana e o Norte de São Gonçalo dos Campos; e o da BR 324 localizado ao longo da BR-324, no Município de Feira de Santana, com 14,2 km de comprimento, a partir do anel de contorno rodoviário, em direção a salvador.

Como tal dinâmica ocorreu fora dos limites das áreas "urbanizadas", carregou consigo novas condições urbano-industriais, que influenciaram a produção e reprodução do espaço geográfico em outras áreas do município. Assim, surge um novo molde para Feira de Santana, que produz contradições sociais, ocasionadas pela atividade industrial, no contexto da desigual sociedade capitalista, como as que podem ser verificadas em Humildes.

A dinâmica industrial que existe nos arredores de Humildes, após a implantação do polo industrial na BR- 324 desenvolve uma realidade espacial específica e apresenta nova dinâmica urbana, sobretudo, porque está localizada próxima do polo, o que torna a vila local de atração de mão de obra. A pesquisa, assim, é importante para a população conhecer a realidade do espaço vivido, acompanhar os avanços que, teoricamente, seriam trazidos pela atividade industrial e pensar novos modelos de planejamento e desenvolvimento urbanos. Sendo assim, também é fundamental por evidenciar as contradições que surgem e precisam 
ser desveladas na estruturação do espaço produzido pela indústria e condição de vida dos moradores.

O tema abrange um recorte local de Feira de Santana, a Vila Humildes, pois a mesma possui uma configuração ímpar a ser pesquisada. Sendo essa a segunda maior cidade do Estado da Bahia, possui aspectos determinantes que contribuem para compreender o desenvolvimento da atividade industrial, já que é sede de um importante polo e possui interrelação com a atuação do Estado nesse setor.

Com base nos argumentos acima, desenvolve-se este trabalho que busca analisar a formação e desenvolvimento de Humildes, a fim de identificar as relações entre a dinâmica econômica e as transformações no espaço urbano ao longo das décadas sob influência da dinâmica industrial ao redor da vila.

\section{METODOLOGIA}

No caso particular desta pesquisa, tem como intuito realizar um estudo que consiste em uma investigação da Vila Humildes, com vistas em prover uma análise do contexto e dos processos envolvidos desde período de sua formação até os dias atuais, com a dinâmica econômica vinculada à atividade industrial.

Assim, foi necessária uma pesquisa documental, para levantamento de dados, que foi feita em órgãos e acervos históricos do município, bem como sem sites oficiais. Essa envolveu a sistematização de registros e coleta de materiais de jornais, bem como de informações sobre datas precisas do período de sua implantação.

A busca em Arquivos Público do Município, Biblioteca Municipal da vila, Acervos da Prefeitura como o IBGE, SEI, que permitiu o acesso a dados para pesquisa documental. A história da vila, em muitos meios de comunicação, é contada por documentos da Igreja Católica. Assim, foram pesquisadas informações publicadas pela Igreja, Revistas antigas e livros.

Ao final da pesquisa, ocorreu uma composição da realidade vigente, em função do desenvolvimento da atividade industrial, associado à acumulação do capital. Com o interesse em compreender o evento em estudo e, ao mesmo tempo, levantar questionamentos a respeito da totalidade, tanto da sociedade, como da realidade social e de suas modificações.

Escolhe-se o materialismo histórico e dialético como método de interpretação, pois esse consiste em investigar acontecimentos, processos e instituições que estão apoiadas na análise da produção do espaço. Tem-se como linha metodológica a compreensão de que é o sujeito e sua relação com a natureza que permite verificar as influências na sociedade atual e suas implicações.

\section{RESULTADOS E DISCUSSÕES}

Muitas são as histórias contadas por morados do distrito de Humildes, que se referem sobre o seu surgimento. Em meio a tantas histórias confabuladas, documentos apontam que a vila Humildes possui mais de duzentos anos, fundada face à construção de uma capela, pelo proprietário da Gameleira, o Romão Gramacho Falcão, que era bandeirante, baiano e devoto de Nossa Senhora dos Humildes. Por volta do século XVIII, iniciou-se a construção da Igreja Matriz, a partir disso, a vila foi crescendo com a vinda das famílias da zona rural para morar na sede, nas casas construídas em volta da igreja para os festejos da Padroeira (IBGE, 1958).

As mais remotas referências sobre Humildes foram encontradas no Livro de Registro de Batizado de São José das Itapororocas. Nesse referido livro, encontra-se registro de um batizado que foi realizada no local que, posteriormente, formou a sede distrito, no dia 24 de março de 1759, uma filial da Matriz de São Gonçalo dos Campos, realizado pelo padre da 
freguesia, Manuel Gonçalves Couto. Tudo leva a crer que esse vigário foi o primeiro a dar assistência à vila. Naquela época, os batizados realizados fora da paróquia eram registrados no local de origem, o que talvez indique que a capela seja ainda mais antiga. Em 1770, também foram encontradas referências sobre a nomeação do Padre José Alves de Cerqueira, como capelão residente, o qual concede licença para várias festas na vizinhança. (É PRECARIA..., 1998).

Com a Resolução Provincial no 794, de 13 de junho de 1859, Humildes, até então filial de São Gonçalo dos Campos, foi desmembrado e elevado à condição de sede paroquial, o que anexou o território à nova jurisdição da Vila de Feira de Santana (É PRECARIA..., 1998).

A Vila de Humildes possui limites tanto ao Norte, quanto Sul, Leste e Oeste, ver mapa 1. Documentos apontam que, por esse motivo, sempre foi cobiçada por imigrantes de outros distritos do município de Feira de Santana. Tendo como vista principal a Matriz de Nossa Senhora dos Humildes, cercada de grades de ferro, bem ao estilo português, no centro de uma larga rua em forma de praça.

Mapa 1: Humildes, Mapa de localização do Distrito

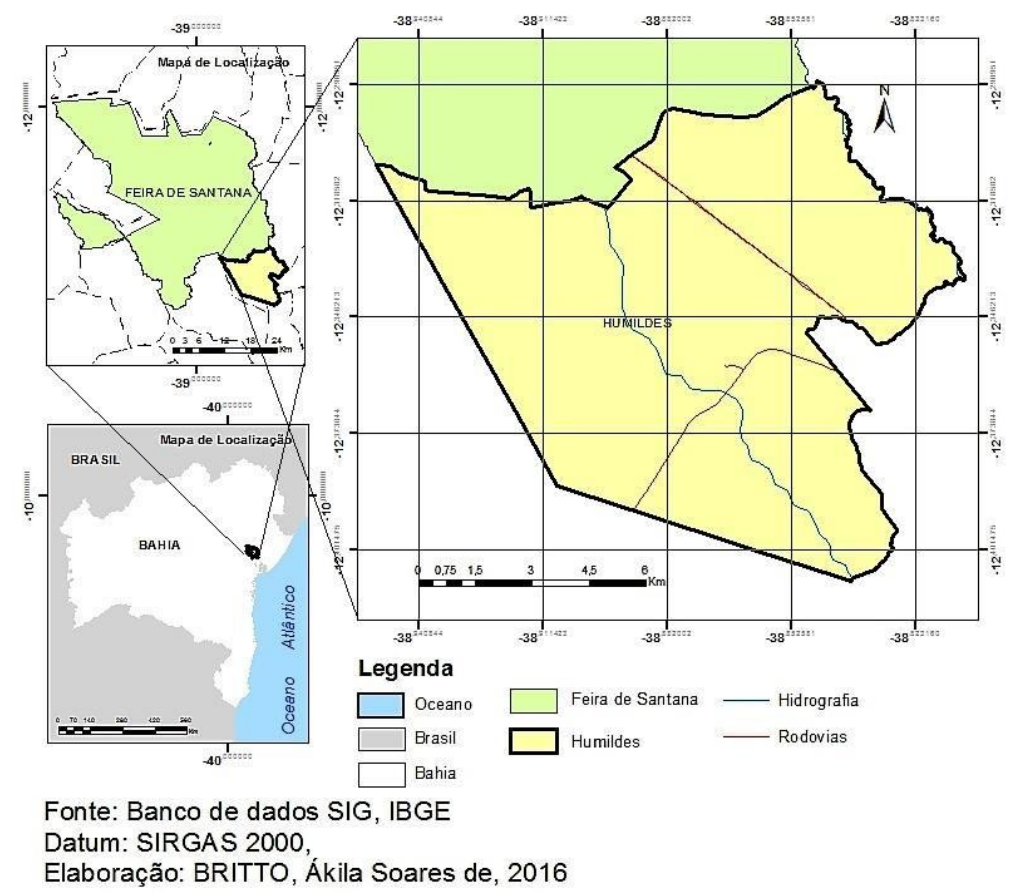

Diante da perspectiva de Santos (2005), o espaço brasileiro está subdividido em urbano e rural, como modo de organizar e pensar o movimento de urbanização e avanço da expansão capitalista no campo. Sendo possível verificar que a vila recebe grandes fluxos migratórios vindos da área rural, como dados apontam que desde 1970-1980 a população começou a se concentrar em áreas urbanas.

Dados do IBGE apontam que a população residente da Vila Humildes teve crescente aumento da população nas últimas décadas. Com esses dados, pode ser levado em consideração que isso ocorreu em função do crescente aumento de indústrias implantadas ao redor de Humildes, que geram maior quantidade de emprego e atraiu mais mão-de-obra para localidade, sobretudo da zona rural.

Com relação ao crescimento de Feira de Santana, vale destacar o papel da indústria como fator importante para a organização espacial da cidade ao longo das décadas. Devido à 
chegada de empresas para o distrito industrial, a cidade se fortaleceu como polo de atração de pessoas, que vêm em busca de melhores condições de vida.

A modernização industrial teve como marco a implantação do Centro Industrial do Subaé (CIS), em 1970, localizado no Bairro do Tomba (CIS -Tomba), e nas margens da BR 324 (CIS - Br. 324), criado através da Lei Municipal n. 690 em 14 de dezembro de 1970. Essas áreas situam-se na parte sul-sudeste da cidade e ocupam posição privilegiada, em decorrência do município ser considerado um dos maiores entroncamentos rodoviários de todo o Norte-Nordeste. Foi criado, inicialmente, pela por uma autarquia, através da Lei Municipal $\mathrm{n}^{\circ} 690$ em 14 de dezembro de 1970. (FREITAS, 1998)

A recente industrialização proporcionou mudanças estruturais na economia baiana, passando o eixo dinâmico, antes centrado na agricultura, para o setor secundário, o que dotou o Estado da capacidade de produzir bens intermediários, com o mercado Sudeste do país na condição de principal. (FREITAS, 1998)

Consequentemente, também alterou a concentração populacional na vila, que implicou no estabelecimento daquilo que se pode denominar de um conjunto de condições gerais da reprodução da força de trabalho, pois, além do sistema de transportes, foram criados sistemas de saúde e educacional, ainda que seja de forma menor que o difundido, quando da instalação das indústrias.

\section{CONSIDERAÇÕES FINAIS}

Sendo assim, é possível afirmar que a vila de Humildes está vinculada a cidade de Feira de Santana, a pesquisa compreende um recorte urbano-industrial de Feira de Santana, por conseguinte, uma realidade espacial específica e apresenta nova dinâmica urbana, sobretudo, por está localizado próximo do Centro Industrial do Subaé (CISBr. 324).

Dessa maneira, a implantação do polo industrial foi de suma importância para o processo de desenvolvimento socioeconômico tanto de Feira de Santana quanto da Vila Humildes. Deste modo, verifica-se o processo de alteração sobre a Vila de Humildes, compreendendo que a indústria não tem relação direta com a formação da Vila. Porém, as mudanças provocadas em Feira de Santana agravam as diferenças sociais e espaciais. Assim, nota-seque expansão que ocorreu na vila, nos últimos anos, apresentando as diferenças sociais e espaciais, são decorrentes do local processo de industrialização, que ajuda a acentuar essas desigualdades socioespaciais.

\section{REFERÊNCIAS}

FREITAS, NB. (1998). Urbanização em Feira de Santana: INFLUÊNCIA da industrialização 1970-1996. Universidade Federal da Bahia: Dissertação (Mestrado em Arquitetura e Urbanismo) Faculdade de Arquitetura.

INSTITUTO BRASILEIRO DE GEOGRAFIA E ESTATÍSTICA (IBGE). Enciclopédia dos Municípios Brasileiros. Rio de Janeiro: IBGE, 1958. Volume XX.

SANTOS, M. (2005). A urbanização Brasileira. São Paulo: Editora da Universidade de São Paulo.

S.I (1998). E Situação precária da Nossa Senhora de HUMILDES. Humildes / Feira de Santana: Folha do Sertão. 